\title{
Short Communication: Seasonal occurrence of the tree locust Anacridium melanorhodon melanorhodon on Acacia senegal in North Kordofan State, Sudan
}

\author{
OMER RAHAMA MOHAMED RAHAMA ${ }^{1}$, MAGZOUB OMER BASHIR AHMED ${ }^{2, \bullet}$, \\ MUTASSIM MOHAMED YASSIN ${ }^{2}$ \\ ${ }^{1}$ Department of Crop Sciences, Faculty of Natural Resources and Environmental Studies, University of Kordofan, Sudan \\ ${ }^{2}$ Department of Crop Protection, Faculty of Agriculture, University of Khartoum. P.O. Box. 32, Khartoum North, Shambat, Sudan, ^email: \\ yamagzoub2@yahoo.com
}

Manuscript received: 19 July 2017. Revision accepted: 28 August 2017.

\begin{abstract}
Rahama ORM, Ahmed MOB, Yassin MM. 2017. Seasonal occurrence of the tree locust Anacridium melanorhodon melanorhodon on Acacia senegal in North Kordofan State, Sudan. Trop Drylands 1: 65-68. The tree locust, Anacridium melanorhodon melanorhodon (Walker, 1870) (Acrididae: Orthoptera) causes sporadic damage mainly to trees. In Sudan, it is called night wanderer because of its nocturnal activity. It is commonly found on the Sudanese western sand plains, causing considerable damage to the gum Arabic producing trees Acacia senegal. The objectives of the study were to investigate the seasonal pattern of the occurrence of tree locusts on A. senegal and factors that influence the tree locust population movements and distribution. Fieldwork was made at an Acacia senegal plantation of the Acacia Project (El Rahad) site, North Kordofan State, during August 2007 and September 2008. The results showed that adults of the tree locust appeared in the field in May and high populations were recorded during the period from June to September reaching the peak $(25.00 \pm 3.08$ per tree $)$ in November. Then the population decreased gradually and disappeared at the end of February. Sexual maturation began during May /June with the first rains and lasted for about four weeks. Oviposition period was during June and July and hoppers, which have six stages, appeared between July and October and their development lasted 1-2 months. The

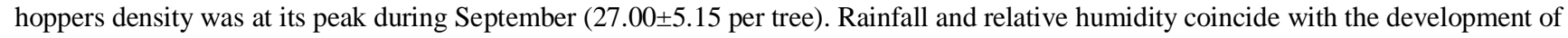
hoppers, while adults were encountered during periods of low rainfall and relative humidity.
\end{abstract}

Keywords: Tree locust, occurrence, North Kordofan, Sudan

\section{INTRODUCTION}

Anacridium melanorhodon melanorhodon (Walker, 1870) (Acrididae: Orthoptera), generally known as Sahelian tree locust, is a pest that causes sporadic damage mainly to trees (COPR 1982). There are twelve species causing the same type of damage in varying degrees to crops, particularly trees (Dirsh and Uvarov 1953). Popov (1989) assumed that A. m. melanorhodon is a mesophilous species that lives primarily in moderately humid habitats, and it is also xerophilous which can live in dry habitats of open forest with thorny trees and shrubs. It is widely distributed in Cape Verde Island, Morocco, Mauritania, Senegal, Mali, Niger, Chad, Nigeria, Ethiopia, Eritrea and Sudan (Uvarov 1923; Johnston 1924, 1932; Tigani 1965; Popov and Ratcliffe 1968). In Sudan, it is called Sahelian tree locust, Sudan tree locust and night wanderer (Popov 1978; FAO 2007). It is distributed in large areas forming a continuous belt from the east to the west spreading over Khartoum, Kassala, White Nile, Blue Nile, Kordofan, Darfur and Northern States (Abdalla 1990; Bashir 1997).

The tree locust is more common in the Sudanese western sand plains and commonly attracts Acacia mellifera and Acacia senegal. Other host plants include trees of the genus Acacia, Balanites aegyptiaca, and Zizyphus spina-christi. Besides the trees of such species, tree locusts also attack the flowers and leaves of fruit trees (e.g. mango, citrus, date palm and guavas). They also feed on vegetables and cause harm to crops such as cotton and sorghum (Schmutterer 1969; SEA 1990) as well as tobacco, maize and millet. It is a serious pest of natural and planted forests (FAO 2007).

The host plants of $A$. m. melanorhodon are scattered in the gum Arabic belt which lies between latitudes $10^{\circ}$ and $15^{\circ} \mathrm{N}$ of semi-arid land across sub-Saharan Africa and receives annual rainfall between $280-450 \mathrm{~mm}$. The infestation of tree locust on A. senegal is devastating since this tree produces Gum Arabic which is the principal source of income in these areas. In addition to gum production, A. senegal tree is used for sand dunes stabilization, microclimate improvement, soil amelioration through nitrogen fixation and a source of firewood and fodder for animals. The economic consequence of the tree locust infestation has been progressively more recognized in many countries, particularly in countries like Sudan, where a great deal of damage was caused by defoliation of A. senegal (El Amin et al. 2008; Eisa et al. 2008). According to (Wewester et al. 1993), A. senegal suffers from the attack of tree locusts especially during years of outbreak. The tree locust feeds on A. senegal leaves leading to low gum productivity. In Sudan, El Zian (1994) mentioned that the loss in gum production caused by tree 
locusts in seasons 1991 and 1992 was estimated at $86.5 \%$ of the total production. Furthermore, (Ballal et al. 2005) recorded that gum Arabic production in Sudan declined due to many factors; including defoliation of trees by tree locust, especially in Kordofan State.

Controlling tree locusts may potentially restore incomes from gum Arabic, boosts foreign exchange earnings, and assist the livestock, forestry, and horticultural industries (SEA 1990). Very few studies have been done on tree locusts in Sudan. It is not known what factors trigger the upsurge of locust population, or whether natural control agents will ultimately reduce the population back to recession levels. This is a potentially valuable area for research (SEA 1990). The objectives of the study are to investigate the seasonal pattern of tree locusts on Acacia senegal in North Kordofan State, Sudan, and factors that influence the tree locust population movements and distribution. This will delineate the period and areas of control, hence avoiding widespread use of pesticides. It also saves effort, time and cost.

\section{MATERIALS AND METHODS}

\section{Study site}

This study was carried out in Al Rahad, $57 \mathrm{~km}$ southeast El Obeid, Sheikan Locality, Northern Kordofan State, during August 2007 - September 2008 in a plantation of $A$. senegal trees with extent of 10.50 ha. Regular surveys of the plantation were conducted twice a week to record tree locust populations during the period from May to October, as well as rainfall and \% relative humidity were regularly recorded.

\section{Data collection of hoppers and adults}

The first hopper stages were counted in the morning between 08:30 and 10:30 h, a period of minimum locust activity, in ten replications of one-meter square each (Luong-Skovmand 2005) and converted to total number per hectare. The second to the sixth instar hoppers were counted in each marked tree using a plastic cup which was placed under a branch, and a stick was used to push the hoppers into the cup. The number of hoppers per tree and the number per hectare were thus determined at each site. Counting of adults was done similarly and was carried out in the morning between 08:30 and 10:30 h. The destructive sampling method was used according to Leather (2005). Fifty trees were selected for adult and hopper counting twice a week.

\section{RESULTS AND DISCUSSION}

\section{Field distribution of adults and hoppers}

Figure 1 shows that A.m. melanorhodon adults appeared in the field in May, which is the beginning of the rainy season. High population density was recorded during June, at which time females gathered at egg laying sites. In July hoppers appeared in reasonable number reaching the peak in September $(27.00 \pm 5.15$ per tree). The adults generated from these nymphs appeared on the field in September reaching the peak in November $(25.00 \pm 3.08$ per tree), but their density decreased gradually, and they finally migrate at the end of February.

\section{Distribution of the different hopper stages}

First hopper stage appeared at the beginning of July and prevailed until mid-August. The second hopper stage appeared in mid-July. There was overlapping between other hopper stages, but the sixth hopper stage appeared during September and October (Figure 2).

\section{Relationship between rainfall and population density of adults and hoppers}

Figure 3 shows that the number of hoppers increased between July and August due to hatching while that of adults decrease because of death after oviposition. In September and October hoppers transform into fledglings adults then the number decreased. Therefore, the number of hoppers increased during the rainy season, but the number of adults decreased.

Figure 4 shows that the mean number of hoppers per tree increased with the increase of $\mathrm{RH} \%$, and the mean number of adults per tree decreased with the increase of RH.

\section{Discussion}

The tree locust, A. m. melanorhodon adults in North Kordofan State appeared in the field in May, and high population density was recorded during June and increased in September reaching the peak in November. Then their density decreased gradually, and they finally disappeared at the end of February. This could be due to the beginning of the rainy season and the accessibility of food throughout these months because all acacia trees completed their greenness, and adult locusts possibly migrated to the other alternative hosts after February. The results agreed with Meinzingen (1993) who reported that the Sahelian tree locust, A.m. melanorhodon, lays eggs during June-July, hoppers develop in August and September, and adults emerge at the end of the rainy season and the onset of the dry season (October and November).

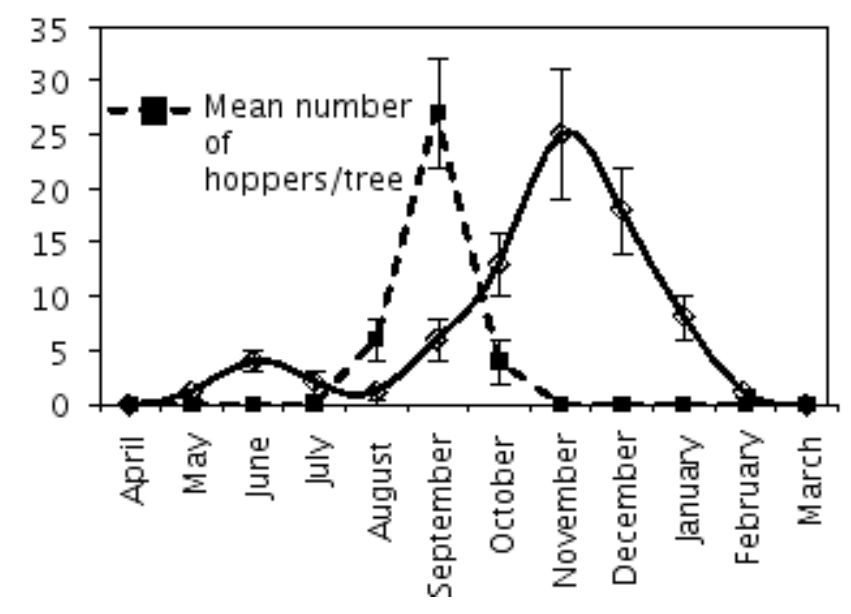

Figure 1. Mean number of the tree locust (adults and hoppers) per tree in the field during seasons from August 2007 to September 2008. 


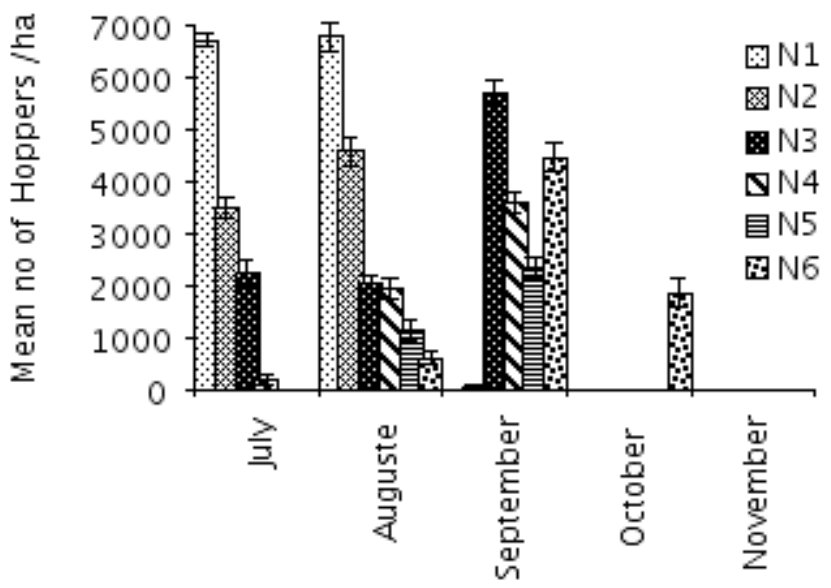

Figure 2. Mean number of the tree locust hopper instars in the field during seasons 2007/08 and 2008/09. N= Hopper nymph stage.

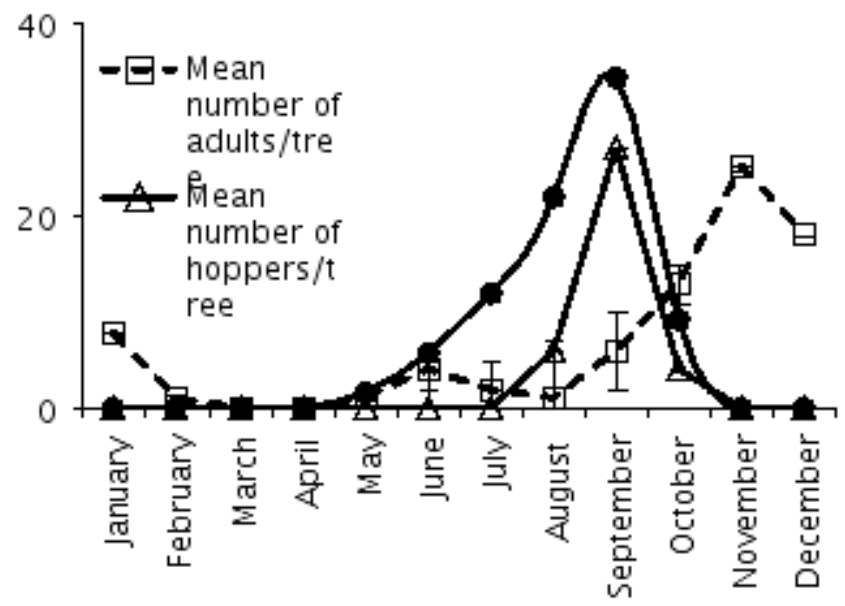

Figure 3. Mean number of the tree locust adults and hoppers per tree in the field in relation to rainfall (seasons 2007/2008 and 2008/2009)

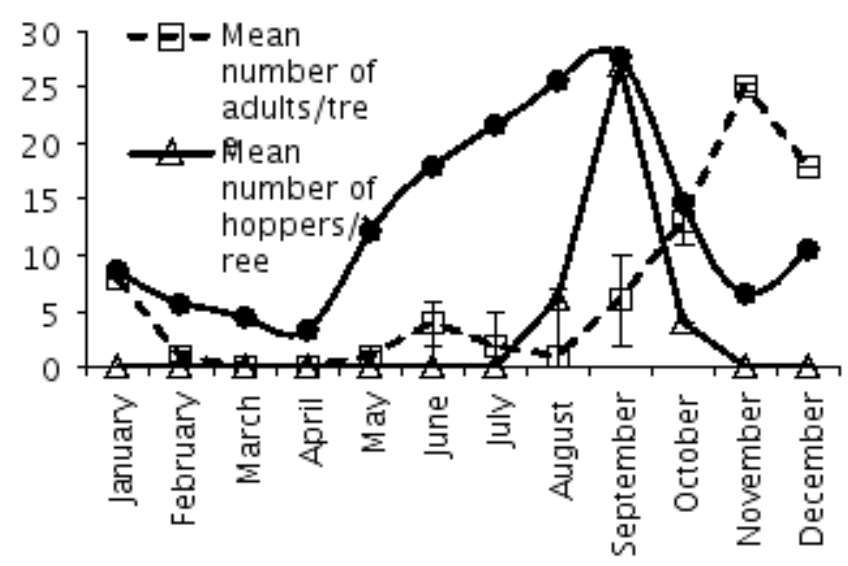

Figure 4. Mean number of the tree locust adults and hoppers per tree in relation to relative humidity (seasons 2007/2008 and 2008/2009)
There were six hopper stages. The first hopper stage appeared at the beginning of July and prevailed until midAugust. The second hopper stage appeared at the mid of July. There was overlapping between other hopper stages, but the sixth hopper stage appeared during September and October. This is because the favorable condition initiates females to lay eggs at that period. These results agreed with Luong and Popov (1997) who reported that imagoes remain in a resting maturation stage until the first rain of the following year in May- June. They took four weeks before copulation, and then females lay eggs and hoppers hatched during the period from July to October.

\section{REFERENCES}

Abdalla AA. 1990. The situation of desert locust, tree locust and grasshoppers in Sudan (1990-1991). In: Lomer CJ. Prior C. (eds) Biological Control of Locusts and Grasshoppers. CAB International, UK.

Ballal ME, El Siddig EA, Elfad MAL, Luukkanen O. 2005. Gum arabic yield in different Acacia senegal stands in Western Sudan, Elobeid. Agrofor Syst 63 (3): 237-245. DOI: 10.1007/s10457-005-4162-x

Bashir El M. 1997. Study on the Biology, Seasonal Occurrence, and Control of the Sahelian Tree Locust Anacridium m. melanorhodon (Walker), Orthoptera: Acrididae. [Thesis]. University of Khartoum, Sudan.

COPR 1982. The locust and Grasshopper Agricultural Manual vii. Centre for Overseas Pest Research, London.

Dirsh VM, Uvarov BP. 1953. Tree locusts of the genus Anacridium (Orthoptera, Acrididae). Revisal Espanola Entomol 29: 7-69.

Eisa MA, Roth A, Sama G. 2008. Acacia senegal (Gum Arabic Tree): Present Role and Need for Future Conservation. Sudan. Programme Tropentag 2008 Competition for Resources in a Changing World New Drive for Rural Development October 7 - 9, 2008, Hohenheim, Germany October 7, 2008.

El Amin HMA, Roth M, Taha ME. 2008. The consequences of defoliation of gum arabic tree (Acacia senegal) by Sahelian tree locust (Anacridium melanorhodon melanorhodon) for the gum producers in North Kordofan State, Sudan. Programme Tropentag 2008 Competition for Resources in a Changing World New Drive for Rural Development October 7 - 9, 2008, Hohenheim, Germany October 7, 2008.

El Zain, ELB. 1994. The impact of defoliation by the tree locust Anacridium melanorhodon melanorhodon Wlk. on the gum Arabic production by hashab tree Acacia senegal. [Thesis]. Faculty of Agriculture, University of Khartoum, Sudan.

FAO. 2007. Forest Health and Biosecurity Working papers FBS/31E, over view of forest pests Sudan. FAO, Rome.

Johnston HB. 1924. A note on locust. Sudan Notes and Records 7: 91 101.

Johnston HB. 1932. Notes on two locusts of minor economic importance in Sudan. Bull Ent Res 23: 49-64. DOI: 10.1017/S0007485300002558

Leather S. 2005. Insect Sampling in Forest Ecosystems. Department of Biological Sciences. Imperial College of Science, Technology, and Medicine. Silwood Park, Ascot, UK. DOI: 10.1002/9780470750513

Luong-Skovmand MH. 2005. Plan de cours Soudan. Training course on Grasshoppers population dynamic. 7 October - 6 November Montpellier, France.

Luong MH, Launois, Popov GB.1997. Anacridium m. melanorhodon (Walker, 1870) Acrididae-Cyrtacanthacridinae. Collaborative work Cirad, DLCO, OCLALAV, Rhone- Poulenc agro.

Meinzingen WF. 1993. A Guide to Migrant Pest Management in Africa. FAO, Rome.

Popov GB. 1989. Nymphs of the Sahelian grasshoppers. (An illustrated guide). Overseas Development Natural Resources Institute, University of Wisconsin, Madison.

Popov GB. 1978. Sahelian Grasshoppers. Overseas Development Natural Resources Institute Bulletin No. 5. University of Greenwich. Chatham, UK 
Popov G, Ratcliffe M.1968. The Sahelian tree locust Anacridium melanorhodon (Walker). Anti-Locust Memoirsno 9: 45.

Schmutterer H. 1969. Pests of Crops in North-east and Central Africa with particular reference to Sudan. Stuttgart Gustav Fischer Verlag, Portland, U.S.A.

SEA 1990. Supplemental Environmental Assessment (SEA) for USAID Funding of Locust or Grasshopper Pesticide in Sudan. USAID, Khartoum.
Tigani MH. 1965. Biology of Poecilocerus heiroglyphicus Klug. and tree locusts of the genus Anacridium in Sudan. [Thesis]. Khartoum University, Sudan.

Uvarov BP. 1923. Notes on locust of economic importance with some new data on the periodicity of locust invasions. Bull Ent Res 14: 3139. DOI: $10.1017 / \mathrm{S} 0007485300028182$

Wewester H, Krail S, Schulz FA. 1993. Methods for the assessment of Crop Losses due to Grasshoppers and Locusts. Technical Corporation Federal Republic of Germany. EFBHEOM-GTZ, Germany. 